\title{
Eric Gatefin, Diderot, Sénèque et Jean-Jacques. Un dialogue à trois voix
}

\section{Bianca Gai}

\section{Q OpenEdition}

1 Journals

\section{Edizione digitale}

URL: http://journals.openedition.org/studifrancesi/8928

DOI: 10.4000/studifrancesi.8928

ISSN: 2421-5856

\section{Editore}

Rosenberg \& Sellier

\section{Edizione cartacea}

Data di pubblicazione: 1 octobre 2008

Paginazione: 460

ISSN: 0039-2944

\section{Notizia bibliografica digitale}

Bianca Gai, «Eric Gatefin, Diderot, Sénèque et Jean-Jacques. Un dialogue à trois voix», Studi Francesi [Online], 155 (LII | II) | 2008, online dal 30 novembre 2015, consultato il 11 janvier 2021. URL: http:// journals.openedition.org/studifrancesi/8928; DOI: https://doi.org/10.4000/studifrancesi.8928

Questo documento è stato generato automaticamente il 11 janvier 2021.

\section{(c) (i) (9)}

Studi Francesi è distribuita con Licenza Creative Commons Attribuzione - Non commerciale - Non opere derivate 4.0 Internazionale. 


\title{
Eric Gatefin, Diderot, Sénèque et Jean- Jacques. Un dialogue à trois voix
}

\author{
Bianca Gai
}

\section{NOTIZIA}

ERIC GATEFIN, Diderot, Sénèque et Jean-Jacques. Un dialogue à trois voix, Amsterdam-New

York, Rodopi, 2007, pp. 398.

1 La prima parte del saggio si concentra sull'analisi dell'Essai sur les règnes de Claude et Neron di Diderot, sul suo andamento dalle movenze spesso contraddittorie, che procede secondo una 'dynamique des contraires' (p. 35) nella costruzione dei personaggi, nell'alternarsi di 'histoire philosophique' e 'histoire héroïque' (p. 53) e nella illustrazione dell'“héroïsme paradoxal” (p. 70) di Seneca. Fin da subito l'autore intravede nel trattamento della materia e nelle strategie di riscrittura del testo, dall'Essai sur la vie de Sénèque alla versione definitiva, quella 'provocation à la lecture active' (p. 124) che pone l'opera diderotiana nello stesso tempo in dialogo e in opposizione con gli scritti di ispirazione autobiografica di Rousseau, soprattutto i Dialogues.

Diderot pare infatti ripercorrere la storia romana rendendo il lettore (così come il narratore) intimamente partecipe agli eventi, mediante l'istituzione di una sorta di effetto di prossimità e il ribassamento del concetto di eroismo alla portata dell'"homme de bien". È postulata così quella necessità di un rapporto senza intermediazione tra il personaggio e il lettore, tra l'uomo e il suo giudice che risulta centrale anche nei dialoghi rousseauiani. La seconda versione del saggio di Diderot poi, si definisce come un "commentaire au second degré" (p. 124), che nelle glosse al primo Essai mostra il pensiero nell'atto stesso del suo costituirsi a margine di un altro testo, così come i Dialogues e le Rêveries prendevano le mosse dalla ricezione delle Confessions. Opere entrambe di giustificazione di un solo uomo, Seneca da una parte e Jean-Jacques dall'altra, Essai e Dialogues sono avvicinati anche nelle modalità di conduzione di tale 
finalità apologetica, che si traduce in una simile abbondanza di termini giudiziari e forme processuali e in un'analoga riflessione sul rapporto che intercorre tra opere e vita del personaggio "giudicato".

3 Eric Gatefin traccia il confronto tra le opere citate di Diderot e Rousseau non solo a partire da somiglianze strutturali. Infatti la novità dello studio risiede nell'interpretazione della celebre citazione dell'Essai sul caso Rousseau, che nel processo di riscrittura si amplia e si inserisce come pausa digressiva all'interno del testo, come elemento funzionale al meccanismo apologetico complessivo dell'opera. In una sorta di mise en abyme rovesciata, la relazione tra Rousseau e i suoi celebratori ripete infatti e inverte la dicotomia Seneca-censori, che a sua volta riprende l'opposizione Diderot-antiphilosophes. L'allusione a Rousseau innesca inoltre un approfondimento della posizione diderotiana sul significato della posterità. Da semplice notazione polemico-autobiografica, l'inserto si trasformerebbe così in una vera $\mathrm{e}$ propria teoria sulla costituzione della memoria umana. Un po' dell'ossessione rousseauiana sulla fragilità dell'opinione dei posteri sembra trasferirsi sulla pagina dell'Essai, che abbandona la posizione ottimistica delle lettere a Falconet. Allo stesso modo Seneca e Jean-Jacques, figure investite di connotazioni sacrali e cristologiche, subiscono l'abuso dell'interpretazione distorta delle proprie opere e della propria memoria da parte dei detrattori. Similmente la verità, concetto instabile e sottoposto a continue ridefinizioni, conosce come unica garanzia il rifugio nella coscienza individuale.

4 Secondo l'autore, tuttavia, l'approdo ultimo della teorizzazione sul significato della posterità, che avvicina Diderot a Rousseau in un ricorso comune alla dimensione individuale, di fronte alla presa di coscienza dell'instabilità della scrittura, ne segna una prima fondamentale distanza. Da una parte si situa la coincidenza diderotiana fra coscienza e razionalità, dall'altra la concezione rousseauiana del dialogo con se stessi come fuoriuscita dalle strettoie del puro logos. Il libro stabilisce in chiusura un ulteriore allontanamento tra i due scrittori: se il ricorso a una dimensione intima conduce Rousseau, soprattutto nelle Rêveries, al precetto dell'écriture pour soi, Diderot recupera invece il contatto con il lettore, che le inquietudini rousseauiane avevano incrinato, nell'ottica di una «éthique de la lecture» (p. 356) modellata sulla costruzione di sé come lettore ideale. Il critico conclude quindi delineando un'immagine di Diderot che, dopo averne condiviso per un attimo e in maniera contraddittoria alcune suggestioni, gira le spalle a Rousseau, avvicinandosi piuttosto alla scrittura pour les autres di Montaigne. 